\title{
A StRATEgic Vision FOR DEVELOPMENT OF FLEXIBLE INDUSTRIAL ENTERPRISE
}

\author{
PANAYFTOVA, T. \& DIMITROVA, K.
}

Abstract: In modern conditions of rapidly developing technology, increasing competition and globalization increasingly becomes clearly outlines the need for flexibility of enterprises. The flexibility of an enterprise is expressed in its ability to react quickly and effectively to market changes and to adapt to the dynamically changing conditions of the external environment, to quickly create and market new and innovative products and services, to meet changing requirements, consumer expectations and needs. In order to remain competitive, companies need to adopt an open technology architecture and collaborate with partners who take advantage of modern solutions of problems. Teams should be open to accepting external experts to manage specific internal functions. Also, companies need to be prepared to integrate data between ecosystems in the way few do today. At the same time, flexible teams with multifunctional skills should be established within the organizations themselves, in order to promote intra-company mobility and the development of individual skills.

Key words: flexibility, intellectual capital, strategic vision, average weight, criteria, sub-criteria, industrial enterprise
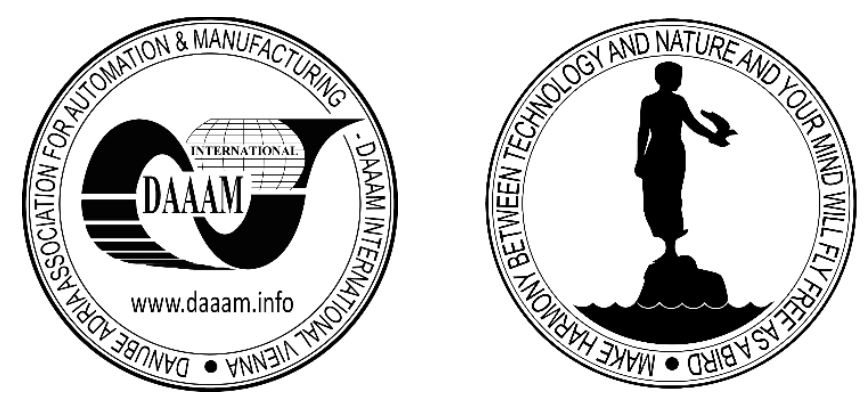

Authors' data: Univ.Prof. Dr. Eng. Panayotova, T[anya]; Univ.Prof. Dr. Eng. Dimitrova, K[rasimira]*, * Technical University of Varna, Studentska str.1, 9010, Varna, Bulgaria, t_panayotova@tu-varna.bg, krasimira.dimitrova@tu-varna.bg

This Publication has to be referred as: Panayotova, T[anya] \& Dimitrova, K[rasimira] (2019). A Strategic Vision for Development of Flexible Industrial Enterprise, Chapter 11 in DAAAM International Scientific Book 2019, pp.143-158, B. Katalinic (Ed.), Published by DAAAM International, ISBN 978-3-902734-24-2, ISSN 1726-9687, Vienna, Austria

DOI: 10.2507/daaam.scibook.2019.11 
Panayotova, T. \& Dimitrova, K.: A Strategic Vision for Development of Flexible In...

\section{Introduction}

In a globalizing and dynamically changing economic realities, businesses are challenged to develop on the basis of the accumulation of knowledge and innovation. Real competitive advantages are sought in the field of product uniqueness and flexibility and change.

The flexibility of the modern enterprise is reflected in the strategies for fragmentation of mass markets in niches, gaining competitive advantages based on the perceived value of the customer, production of multiple products and services in different market quantities, designing solutions interactively with customers, organizing change and rapid response, leadership leadership, motivation, support and trust, full use of information and communication technologies, capabilities, resources and assets, independent In addition to their location, they work through teams of entrepreneurship, partnerships with other companies (Sushil \& Chroust, 2014), (Sushil \& Edward, 2013).

The flexibility of an industrial enterprise can be defined as strategic, organizational, financial, production flexibility, versatility of information systems, flexibility, marketing, operational flexibility, flexibility in the management of technology, etc. (Dimitrova et al., 2019). Tools and measures of flexible enterprises:

- Transaction analysis

- Cost chains for different activities

- Customer orientation

- Organizational maps

- Information system and virtual collaboration

- Highly qualified specialists

- Internet Challenges and Opportunities for Business

- Dependence on intellectual capital

The dependency of enterprise flexibility on intellectual capital management is becoming increasingly tangible. At the same time, there is a need to seek strategic solutions to achieve a higher level of competitiveness through a flexible approach to intellectual capital. In this study, measuring the flexibility of industrial enterprise will be associated with dependence on the management of intellectual capital as a source of flexibility for industrial firms through innovation as they provide a key basis for establishing competitive advantage. (Markovic et al., 2018).

In order to analyze the flexibility of industrial enterprises in Bulgaria through the resources of intellectual capital, statistical information from the National Statistical Institut for 2018 has been studied and analyzed. From the analyzed quantitative data on the opportunities for managing intellectual capital in industrial enterprises in Bulgaria, it can be summarized that there are undisclosed / unused ways to use the basic functions of intellectual capital in the business cycle of enterprises. Industrial enterprises need support and specific measures to improve the management of intellectual capital. On the Fig. 1-5 are vizualized data from National Statistical Institut (Dancheva et al., 2019) 


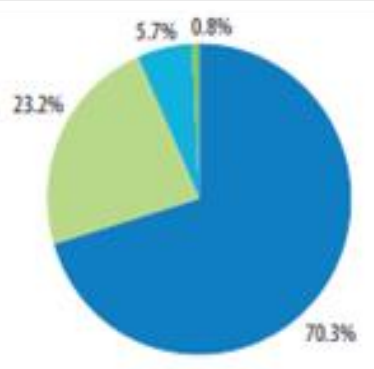

Business enterprises sector

Government sector

Higher education sector

Private non-profit sector

Fig. 1. Research and development activity and innovation activity.

\begin{tabular}{|l|r|r|r|r|}
\hline & 2014 & 2015 & 2016 & 2017 \\
\hline GERD - thousand BGN & 664829 & 850457 & 734274 & 760234 \\
\hline Current costs & 587491 & 735207 & 654779 & 691428 \\
\hline Capital expenditure & 77338 & 115250 & 79495 & 68806 \\
\hline $\begin{array}{l}\text { R\&D expenditure as a } \\
\text { percentage of GDP - \% }\end{array}$ & 0.79 & 0.96 & 0.78 & 0.75 \\
\hline
\end{tabular}

Fig. 2. Gross domestic expenditure on research and development activity (GERD) by type of costs.

\begin{tabular}{|l|r|r|r|r|}
\hline Categories & 2014 & 2015 & 2016 & 2017 \\
\hline & \multicolumn{4}{|c|}{ Headcount } \\
\hline Total & 25484 & 29591 & 32306 & 31221 \\
\hline Researchers & 17795 & 19338 & 21081 & 20971 \\
\hline Other R\&D personnel & 7689 & 10253 & 11225 & 10250 \\
\hline & \multicolumn{5}{|c}{ Full-time equivalent } \\
\hline Total & 19335 & 22492 & 25060 & 23290 \\
\hline Researchers & 13201 & 14236 & 16001 & 15094 \\
\hline Other R\&D personnel & 6134 & 8256 & 9059 & 8196 \\
\hline
\end{tabular}

Fig. 3. Personnel engaged in research and development activity (R\&D) by category.

\begin{tabular}{|l|r|}
\hline Economic sectors & \\
\hline Total & 27.2 \\
\hline Industry & 31.6 \\
\hline Mining and quarrying & 23.7 \\
\hline Manufacturing & 31.8 \\
\hline Electricity, gas, steam and air conditioning supply & 37.7 \\
\hline Water supply; sewerage, waste management and remediation activities & 25.7 \\
\hline Services & 22.1 \\
\hline Wholesale trade, except of motor vehicles and motorcycles & 18.9 \\
\hline Transportation and storage & 11.5 \\
\hline Information and communication & 44.4 \\
\hline Financial and insurance activities & 28.3 \\
\hline Architectural and engineering activities; technical testing and analysis & 21.8 \\
\hline Scientific research and development & 100.0 \\
\hline Advertising and market research & 18.0 \\
\hline
\end{tabular}

Fig. 4. Innovative enterprises as a share of all enterprises in 2016. 
Panayotova, T. \& Dimitrova, K.: A Strategic Vision for Development of Flexible In...

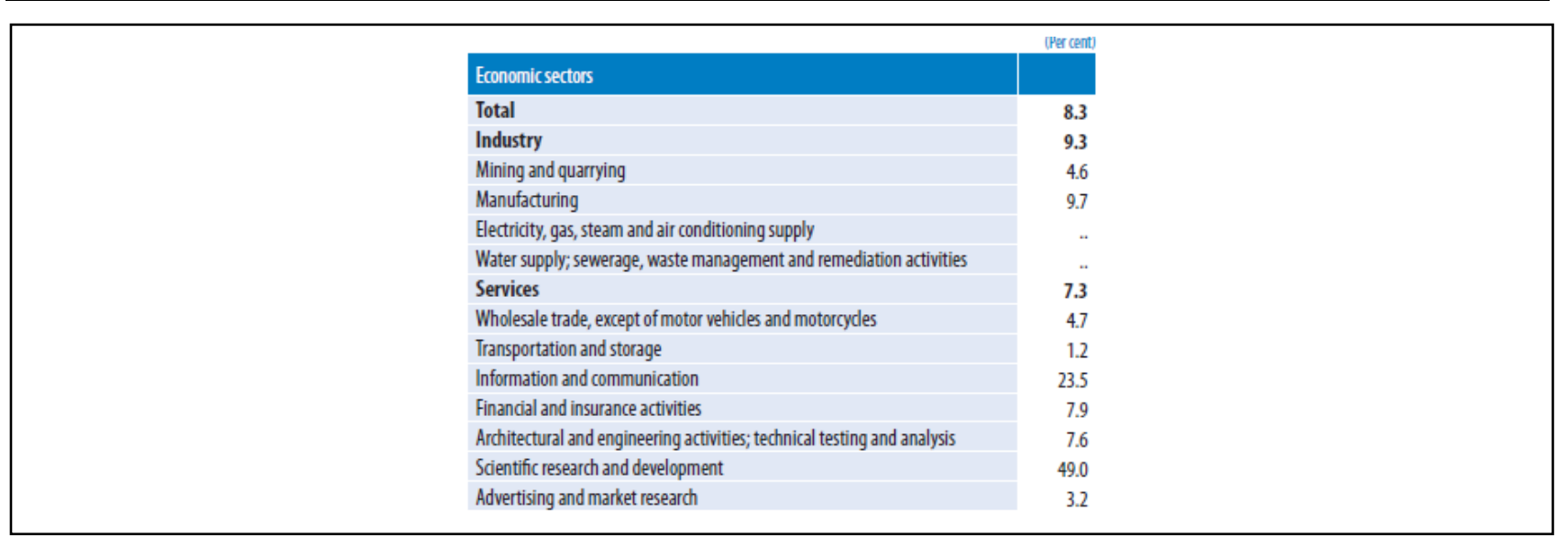

Fig. 5. Enterprises that have new or significantly improved products new to the market as a share of all enterprises in 2016.

The main challenges facing the industrial enterprises in Bulgaria on their way to flexibility and adaptability are emerging: (Schwab, 2018)

- improving the skills of the workforce;

- shortage of personnel in the sectors determining the development of the digital economy;

- low share of spending in education and R\&D;

- lack of sufficient examples of successful cooperation between the education system and business.

The main problem explored in this study is the impact of intellectual capital in forming the strategic vision for development of a flexible industrial enterprise.

To solve this problem, the tasks assigned are related to establishing the efficiency of the implementation of intellectual capital and defining the tools and measures of flexibility of industrial enterprises through the elements of intellectual capital. Analytical hierarchic process (AHP) is used as a main tool for selection and evaluation of criteria, taking into account the power of influence of internal and external factors on the activity of the enterprise and its flexibility.

\section{Effectiveness of the application of Intellectual capital}

The measurement and management of intellectual capital requires adequate management strategies in modern companies. Without knowledge and identification of the factors affecting the value of their intellectual capital, which accounts for the bulk of their market value, it is not possible to develop and implement knowledgebased innovations.

In order to remain competitive, companies need to adopt an open technology architecture and collaborate with partners who take advantage of modern solutions of problems. According to many researchers and analysts, teams should be open to accepting external experts to manage specific internal functions. In addition, companies need to be prepared to integrate and share data between ecosystems in the way few do today. At the same time, flexible teams with multifunctional skills should be established within the organizations themselves, in order to promote intracompany mobility and the development of individual skills. 
The management of intellectual capital activities requires that the available information have to be organized in an orderly perspective.

Intellectual assets can be considered in three categories (www.bontis.com): Human capital, Structural capital, Client capital.

- Human capital includes the knowledge, skills, motivation and experience of the people in the organization. This is the human side of the organization. Human capital is not owned by the organization, it only hires it. An organization can enhance the quality of its human capital by applying different methods of employee training.

- Structural capital is the infrastructure that supports human capital. This is the medium for reproducing human capital. It consists of processes, copyrights, patents, technologies, organizational culture, communication within the organization, strategies, etc. Unlike human capital, structural capital is the property of the organization.

- Client capital. Although this category is called client capital, it does not refer solely to clients. In addition to customer relationships, this also includes relationships with the external environment - suppliers, strategic partners and all other stakeholders. The value of the client's capital depends on the reputation of the company, on the loyalty and satisfaction of the clients, on the long-term relations with partners, on the presence of strategic partnerships, etc.

One of the major problems associated with accounting and measuring intellectual capital is the fact that its core elements are difficult to formalize and measure. They can be described by a set of specific characteristics, which are rather qualitative in nature (Tab. 1).

\begin{tabular}{|l|l|l|}
\hline \multicolumn{1}{|c|}{ Human capital } & Structural capital & Client capital \\
\hline- knowledge & - processes & - customer loyalty \\
- skills & - patents, copyrights, & - long term \\
- education & trademarks & - customer \\
- creativity & - corporate culture & relationships \\
- learning abilities & - management & - reputation of the \\
- loyalty & philosophy & company, image \\
& - corporate strategies & - relationships with \\
& - Information & suppliers \\
& Technology & relationships with \\
& & partners and other \\
& & stakeholders \\
\hline
\end{tabular}

Tab. 1. Components of Intellectual capital.

Taking into account the analyzes and comments on the three elements of the Intellectual capital concept listed above, it is concluded that they are in continuous interaction with each other and should be considered together in one dynamic 
equilibrium. It is impossible to identify only one of them, in isolation, without affecting a decision related to at least one of the others, or simply making that information necessary for them. It follows that the creation of wealth for the organization is based on a chain of transfers, i.e. individual knowledge and skills (human capital) in organizational knowledge and practices (structural capital), which subsequently affects client capital by providing new products and services.

The contribution of intellectual capital to the company is expressed in revenues from products and services, reputation and image, providing access to the technology of others, preventing infringement of foreign intellectual property rights, freedom to design, reducing costs, barriers to competition, building customer loyalty, innovation protection. On this basis, the logical sequence of the main processes for improving the management of intellectual capital can go through the following basic steps (Panayotova, 2016):

a) Defining the system and the field: the improvement of intellectual capital can be focused on the whole company, individual business unit or any part of it;

b) Indication of all system elements: identification of sources of value;

c) Investigation of the links between the sources of value;

d) Construction of a source tree scheme of value;

e) Determination of their relative importance;

f) Qualitative and quantitative assessment of the impact of individual identified sources on resource categories;

g) Determining the location of the sources of value and their interaction;

h) Formation of of intellectual capital management strategies.

\section{Instruments and measures of flexibility of industrial enterprises through the elements of Intellectual capital}

In determining the position of flexibility and developing a strategic vision for the development of an industrial enterprise, it is necessary to take into account the effects of the interaction of the three components of the intellectual capital that fulfill the role of selection criteria. (Bernardes \& Hanna, 2009), (Brown \& Bessant, 2003), (Coulson, 2002).

These criteria form a system, and each of them may have its own sub-criteria. The simultaneous consideration of the multiple criteria and their sub-criteria provides greater precision in the final evaluations, but makes it difficult to define them. In their practice, businesses can face two major problems. The first one is related to the proper definition of the evaluation criteria (influencing factors) and their sub-criteria, and the second - to the simultaneous consideration of their performance. There are relatively few examples in the literature that address these issues (Pulic, 2004), (Roos et al., 2005), (Stevenson \& Ozgur, 2007).

An in-depth analysis of publications on the issue leads to the conclusion that it needs to be proposed:

(1) way of forming a comprehensive system of decision criteria for choosing a strategy for increasing the flexibility and adaptability of an industrial enterprise with an emphasis on the impact of intellectual capital; 
(2) method and toolkit by which to take into account the extent to which the strategy chosen satisfies the other sub-criteria in the criterion determined with the highest relative weight.

\section{Criteria for deciding on the degree of flexibility}

To solve the first problem here is the proposed system of criteria for evaluation and selection. Their specific meanings, taking into account the power of influence of internal and external factors, depend on the peculiarities of the activity of the enterprises and the conditions of the environment in which it takes place. The system is based on some of the most common objective indicators for each category of intellectual property offered by (Liebowic \& Ching, 2000), part of which, in the present study have been modified and includes:

\subsection{Degree of influence of Human capital}

3.1.1. Key Employee Retention Rate

The percentage of employees who are critical to the organization and retained during the previous year.

3.1.2. Ability to attract highly qualified employees

The percentage of job vacancies that require significant experience and high qualification and which were filled in the previous year.

3.1.3. Computer literacy rate

The percentage of employees who have a predefined level of advanced technology skills.

\subsubsection{Key Personnel Replacement Cost}

The average cost of recruiting, recruiting, hiring, and training a person who holds a key position in an organization.

\subsubsection{Employee Satisfaction Rate}

The percentage of employees who have a high level of job and organization satisfaction.

3.1.6. Degree of employee initiative

The amount of ideas proposed / initiated by employees over a given period.

\subsection{Degree of influence of Structural capital}

3.2.1. Degree of alignment of the goals and strategies of the enterprise:

- Expected increase in sales;

- Expected reduction in production and sales costs;

- Expected increase in the profit of the enterprise;

- Expected rate of return on additional investment;

- Degree of alignment of enterprise strategies.

3.2.2. Degree of conformity of the production capabilities of the enterprise:

- Degree of technical and technological capabilities of enterprise;

- Innovative enterprise capabilities to quickly meet customer requirements; 
Panayotova, T. \& Dimitrova, K.: A Strategic Vision for Development of Flexible In...

- Degree of modularity of the products. The higher modularity of the products implies a greater variability of the products and a higher degree of individualization. Provides easier implementation of co-creation and codevelopment practices;

- Degree of process flexibility. Flexibility of product creation processes is also a prerequisite for greater variability and individualization;

- Information and communication opportunities for the implementation of the practice for customer involvement in the process of product creation and delivery.

\subsubsection{Research Expenditure}

The cost of developing new products and services in the previous year.

3.2.4. Percentage of employees engaged in innovative activity

The percentage of employees responsible for developing new products and services.

\subsubsection{Product Novelty}

The percentage of products / services that have been introduced on the market over the last 2-3 years.

\subsubsection{Process Documentation}

The extent to which core business processes are described and continually improved.

\subsubsection{Process quality}

For example, the time from receipt of a customer request to the delivery of the final product over the scheduled time.

\subsection{Degree of influence of Client capital}

\subsubsection{Customer Satisfaction}

The percentage of customers who are highly satisfied with the products or services provided.

\subsubsection{Quality of products and services}

The percentage of customers who have complaints about the products and services provided; customer refunds.

\subsubsection{Average customer relationship duration}

The average number of years that existing customers purchase an organization's products and services.

\subsubsection{Order Repeatability}

Percentage of current customers who have previously purchased an organization's products and services.

\subsubsection{Image Customers}

Percentage of sales to customers who have a positive image of the organization.

3.3.6. Degree of compliance with the requirements of the buyer.

The more non-standard the product is and reflects the individual requirements of consumers, the more profitable it is for them. For standard products this need is low. The degree of customer interaction required varies depending on whether the entity offers a material product or service. 


\subsubsection{Degree of technological integration with the buyer.}

Higher technological connectivity with the buyer requires closer interaction with the buyer.

3.3.8. Degree of development of contacts with buyers.

In the production and delivery of industrial products, contacts with buyers are much more direct and strong. It is often manufactured to specifications and agreed specifications.

3.3.9. Degree of technical complexity of the product.

The technical complexity and complexity of the product requires much greater involvement of the buyer in the creation, production and delivery of the product. Strong interaction with the manufacturer is required.

3.3.10. Degree of variety of product variants.

The wide variety of variants and quality characteristics of the product requires better compliance with consumer requirements and closer interaction with buyers. It often leads to the realization of "co-creation" and "co-development" opportunities. 3.3.11. Degree of compliance with consumer requirements.

The rapidly changing consumer demands, the deepening of the fragmentation of the markets, leading to the need to meet the specific requirements of small groups of consumers, provoke responses from manufacturers;

3.3.12. Degree of customer demand for opportunities to participate in the process of product creation and delivery;

3.3.13. Technology opportunities for customers to participate in the process of product creation and delivery;

3.3.14. Company's reputation as a loyal partner.

A better reputation for the company as a loyal, innovative and quality partner is a prerequisite for closer customer engagement.

These criteria may be modified and supplemented according to the specific conditions in which the entity operates.

The set of indicators depends solely on the industry in which the organization operates. Each organization should develop indicators that meet the specificities of its activities. (Panayotova et al., 2011)

\section{Methodology for taking into account the impact of individual criteria}

The second major problem is the simultaneous consideration of the many criteria and sub-criteria used. Addressing it requires an assessment of the impact of each of the criteria and sub-criteria, an assessment of their importance for achieving the desired outputs from the enterprise. In doing so, the method of evaluation and choice must prevent or at least minimize the potential for error and subjectivity in the final decisions. Consideration of the impact of individual criteria should include a series of judgments and decisions that have a hierarchical structure, as shown in Fig. 6.

The hierarchy of decisions requires the definition of a goal that is related to determining the impact of individual criteria on the flexibility of an industrial 
Panayotova, T. \& Dimitrova, K.: A Strategic Vision for Development of Flexible In...

enterprise and identifying the criteria and sub-criteria that affect its achievement. The impact of each of the criteria and sub-criteria must be evaluated so that they can be ranked by importance in formulating alternative strategies for the development of a flexible industrial enterprise.

In order to facilitate the selection process and to avoid, or at least significantly reduce, subjectivity in making final decisions, it is advisable to use specially developed assessment and selection methods and software. Method of Analytical Hierarchic Process (AHP) is also suitable for this purpose (Saaty, 1980).

AHP method is a useful tool for selecting alternative to using multiple criteria, especially when criteria have sub. It makes a choice based on the relative importance of the criteria for achieving the goals of the enterprise.

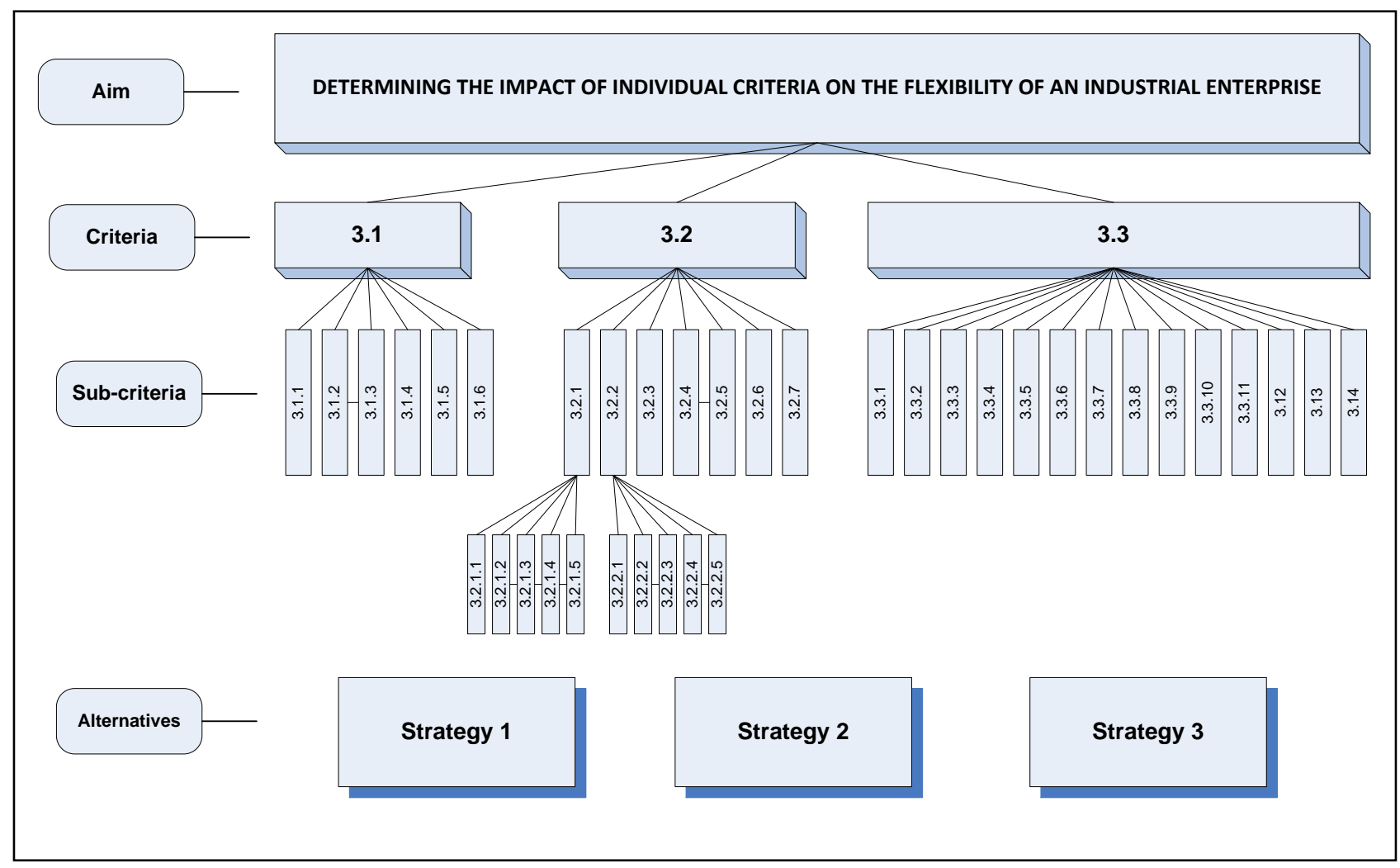

Fig. 6. Hierarchy of decisions in determining the impact of individual criteria on the flexibility of an industrial enterprise.

According to the AHP procedure, determining the relative weight of the selection criteria starts with their comparative assessment in pairs. This is done by a group of experts who use the assessment scale shown in Tab. 1 (Stevenson \& Ozgur, 2007).

The criteria and sub-criteria are compared in pairs in terms of their importance for achieving the next higher level of criteria and goals. The comparison by relative priority of the criteria each to other is done in order to achieve the desired objective or criterion on a higher level. 


\begin{tabular}{|l|c|}
\hline \multicolumn{1}{|c|}{ Degree of Relative Importance } & Score \\
\hline Equal Importance & 1 \\
\hline Between Equal and Moderate Great Importance & 2 \\
\hline Moderate Great Importance & 3 \\
\hline Between Moderate Great and Great Importance & 4 \\
\hline Great Importance & 5 \\
\hline Between Great and Very Great Importance & 6 \\
\hline Very Great Importance & 7 \\
\hline Between Very Great and Extremely Great Importance & 8 \\
\hline Extremely Great Importance & 9 \\
\hline
\end{tabular}

Tab. 2. Scale for determining the importance (priority).

The comparison stands for the relative importance of a certain criterion in relation to another one, in order to achieve that specific aim or in relation to another criterion at a higher level.

The levels of relative importance determined by the experts should be checked for inconsistency. If there is an inconsistency out of permitted boundaries, then the estimates should be reviewed. This is done by calculating the following ratio (Saaty, 1980)

$$
C R=\frac{C I}{R I}
$$

CR - Consistency Ratio,

CI - Consistency Index,

RI - Random Index - defined according to the number (n) of objects compared in the following table (Panayotova, 2004):

\begin{tabular}{|c|c|c|c|c|c|c|c|c|c|}
\hline $\mathbf{n}$ & 2 & 3 & 4 & 5 & 6 & 7 & 8 & 9 & 10 \\
\hline $\mathbf{R I}$ & 0 & 0,58 & 0,90 & 1,12 & 1,24 & 1,32 & 1,41 & 1,45 & 1,49 \\
\hline
\end{tabular}

Tab. 3. Random Index defined according to the number (n) of objects

$$
C I=\frac{\lambda-n}{n-1}
$$

$\lambda$ - Largest Eigen Value

The comparisons are considered to be consistent, when $\mathrm{CI}<0,10$. (Handfield at al., 2002).

This paper aims conditional example to demonstrate the applicability of AHP method for determining the relative weighting of criteria. An alternative strategy must be chosen, depending on the relative importance of the criteria. The development of an alternative strategy will be tailored to the weight of the relevant sub-criteria and their degree of influence on the relevance of each criterion.

As a result of the expert group discussions on criteria 3.1 to 3.3, the following matrix for comparing their importance pair wise is suggested: 
Panayotova, T. \& Dimitrova, K.: A Strategic Vision for Development of Flexible In...

\begin{tabular}{|c|c|c|c|}
\hline Criterion & 3.1. & 3.2. & 3.3. \\
\hline 3.1. & 1,00 & 2 & 6 \\
\hline 3.2. & 0,50 & 1 & 2 \\
\hline 3.3. & 0,17 & 0,5 & 1 \\
\hline
\end{tabular}

Tab. 4. Comparing criteria pair wise with respect to the objective

After normalizing and calculating the first normalized principal Eigen vector, we come to the following distribution of priorities of the criteria:

\begin{tabular}{|c|c|c|c|c|}
\hline Criterion & 3.1. & 3.2. & 3.3. & Average weight \\
\hline 3.1. & 0,5988 & 0,5714 & 0,6667 & 0,6123 \\
\hline 3.2. & 0,2994 & 0,2857 & 0,2222 & 0,2691 \\
\hline 3.3. & 0,0998 & 0,1429 & 0,1111 & 0,1179 \\
\hline
\end{tabular}

Tab. 5. Calculating criteria priorities with respect to the objective

Tab. 4 shows that most relative importance is the first criterion, namely (3.1.) Degree of influence of human capital. In order to determine the reliability of the results obtained, it is necessary to make additional calculations.

\begin{tabular}{|c|c|c|c|c|c|c|}
\hline Criterion & 3.1. & 3.2. & 3.3. & $\begin{array}{c}\text { Average } \\
\text { weight }\end{array}$ & $\begin{array}{c}\text { Total } \\
\text { weight }\end{array}$ & Priority \\
\hline 3.1. & 0,5988 & 0,5714 & 0,6667 & 0,6123 & 1,858062 & 3,035 \\
\hline 3.2. & 0,2994 & 0,2857 & 0,2222 & 0,2691 & 0,811108 & 3,014 \\
\hline 3.3. & 0,0998 & 0,1429 & 0,1111 & 0,1179 & 0,354529 & 3,006 \\
\hline
\end{tabular}

Tab. 6. Average and total weight of criteria calculation.

Calculations show that Consistency Ratio is within the limit: $C R=0,01581117$ $<0.1$. What follows is to determine the relative importance among the pairs of subcriteria for each criterion. A view on the present example is shown in Tables 3 to 8:

\begin{tabular}{|c|c|c|c|c|c|c|c|}
\hline Sub-Criteria & 3.1.1. & 3.1.2. & 3.1.3. & 3.1.4. & 3.1.5. & 3.1.6. & $\begin{array}{c}\text { Average } \\
\text { weight }\end{array}$ \\
\hline 3.1.1. & 0,1026 & 0,1053 & 0,2759 & 0,0714 & 0,2807 & 0,0244 & 0,1434 \\
\hline 3.1.2. & 0,2051 & 0,2105 & 0,4138 & 0,2857 & 0,2807 & 0,1951 & 0,2652 \\
\hline 3.1.3. & 0,0513 & 0,0702 & 0,1379 & 0,2857 & 0,2807 & 0,0976 & 0,1539 \\
\hline 3.1.4. & 0,2051 & 0,1053 & 0,0690 & 0,1429 & 0,0702 & 0,1951 & 0,1313 \\
\hline 3.1.5. & 0,0256 & 0,0526 & 0,0690 & 0,1429 & 0,0702 & 0,3902 & 0,1251 \\
\hline 3.1.6. & 0,4103 & 0,1053 & 0,0345 & 0,0714 & 0,0175 & 0,0976 & 0,1228 \\
\hline
\end{tabular}

Tab. 7. Comparing sub-criteria 3.1.1. - 3.1.6. pair wise with respect to the criterion 3.1. Inconsistency: 0.071 


\begin{tabular}{|l|l|l|l|l|l|l|l|r|}
\hline Sub-Criteria & 3.2.1. & 3.2.2. & 3.2.3. & 3.2.4. & 3.2.5. & 3.2.6. & 3.2.7. & $\begin{array}{r}\text { Average } \\
\text { weight }\end{array}$ \\
\hline 3.2.1. & 0,3300 & 0,5146 & 0,3200 & 0,2554 & 0,2567 & 0,2326 & 0,173913 & 0,2976 \\
\hline 3.2.2. & 0,1089 & 0,1715 & 0,3200 & 0,2554 & 0,1926 & 0,1860 & 0,173913 & 0,2012 \\
\hline 3.2.3. & 0,1650 & 0,0858 & 0,1600 & 0,2554 & 0,2567 & 0,1860 & 0,173913 & 0,1833 \\
\hline 3.2.4. & 0,1650 & 0,0858 & 0,0800 & 0,1277 & 0,1926 & 0,1860 & 0,173913 & 0,1444 \\
\hline 3.2.5. & 0,0825 & 0,0566 & 0,0400 & 0,0421 & 0,0642 & 0,1395 & 0,173913 & 0,0856 \\
\hline 3.2.6. & 0,0660 & 0,0429 & 0,0400 & 0,0319 & 0,0212 & 0,0465 & 0,086957 & 0,0479 \\
\hline 3.2.7. & 0,0825 & 0,0429 & 0,0400 & 0,0319 & 0,0160 & 0,0233 & 0,043478 & 0,0400 \\
\hline
\end{tabular}

Tab. 8. Comparing sub-criteria 3.2.1 -3.2.7 pair wise with respect to the criterion 3.2. Inconsistency: 0.049

\begin{tabular}{|c|c|c|c|c|c|c|}
\hline Sub-Criteria & $\mathbf{3 . 3 . 1}$ & $\mathbf{3 . 3 . 2}$ & $\mathbf{3 . 3 . 3}$ & $\mathbf{3 . 3 . 4}$ & $\mathbf{3 . 3 . 5}$ & Average weight \\
\hline $\mathbf{3 . 3 . 1}$ & 0,1739 & 0,1936 & 0,2143 & 0,1225 & 0,2500 & 0,1910 \\
\hline $\mathbf{3 . 3 . 2}$ & 0,3478 & 0,3871 & 0,3214 & 0,4898 & 0,2500 & 0,3590 \\
\hline $\mathbf{3 . 3 . 3}$ & 0,0870 & 0,1289 & 0,1072 & 0,0816 & 0,1875 & 0,1180 \\
\hline $\mathbf{3 . 3 . 4}$ & 0,3478 & 0,1936 & 0,3214 & 0,2449 & 0,2500 & 0,2720 \\
\hline $\mathbf{3 . 3 . 5}$ & 0,0435 & 0,0968 & 0,0357 & 0,0612 & 0,0625 & 0,0600 \\
\hline
\end{tabular}

Tab. 9. Comparing sub-criteria 3.3.1 - 3.3.5 pair wise with respect to the criterion 3.3. Inconsistency: 0.042

Depending on the results of the average weights of individual criteria and subcriteria, they can be ranked in order to establish the degree of their impact on the flexibility of the industrial enterprise.

At present conditional example shows that the largest relative importance has the highest criterion "Degree of influence of the human capital" in terms of flexibility of industrial enterprise. According to the proposed methodology, ranking of these sub-criteria can be seen in Tab. 9

\begin{tabular}{|c|c|}
\hline Sub-criteria in criteria 3.1 & $\begin{array}{c}\text { Ranking of sub-criteria by importance } \\
\text { (weight) }\end{array}$ \\
\hline 3.1.2. & 0,2652 \\
\hline 3.1.3. & 0,1539 \\
\hline 3.1.1. & 0,1434 \\
\hline 3.1.4. & 0,1313 \\
\hline 3.1.5. & 0,1251 \\
\hline 3.1.6. & 0,1228 \\
\hline
\end{tabular}

Tab. 10. Ranking of the sub-criteria in criterion 3.1. 
Panayotova, T. \& Dimitrova, K.: A Strategic Vision for Development of Flexible In...

Second in importance is the criterion "Degree of impact of the structural capital". The ranking of the respective sub-criteria is illustrated in Tab. 10.

\begin{tabular}{|c|c|}
\hline Sub-criteria in criteria 3.2 & $\begin{array}{c}\text { Ranking of sub-criteria by importance } \\
\text { (weight) }\end{array}$ \\
\hline 3.2.1. & 0,2976 \\
\hline 3.2.2. & 0,2012 \\
\hline 3.2.3. & 0,1833 \\
\hline 3.2.4. & 0,1444 \\
\hline 3.2.5. & 0,0856 \\
\hline 3.2.6. & 0,0479 \\
\hline 3.2.7. & 0,04 \\
\hline
\end{tabular}

Tab. 11. Ranking of the sub-criteria in criterion 3.2.

On the third place, the criterion "Degree of impact of the client capital" is ranked by sub-criteria. Ranking the relevant sub-criteria is illustrated in Tab. 11.

\begin{tabular}{|c|c|}
\hline Sub-criteria in criteria 3.3 & $\begin{array}{c}\text { Ranking of sub-criteria by importance } \\
\text { (weight) }\end{array}$ \\
\hline 3.3.2. & 0,359 \\
\hline $\mathbf{3 . 3 . 4 .}$ & 0,272 \\
\hline $\mathbf{3 . 3 . 1}$ & 0,191 \\
\hline $\mathbf{3 . 3 . 3}$ & 0,118 \\
\hline $\mathbf{3 . 3 . 5}$ & 0,06 \\
\hline
\end{tabular}

Tab. 12. Ranking of the sub-criteria in criterion 3.3.

As a result of rankings of the individual criteria and sub-criteria, the extent to which they satisfy the requirements for flexibility of the industrial enterprise and the contribution of the Intelectual capital to its formation can be determined.

Aggregate assessments can help managerial decision making in developing alternative strategies for the development of a flexible industrial enterprise

\section{Conclusions}

In the modern conditions of rapidly developing technologies, increasing competition and globalization, more clearly outlines the need for flexibility of enterprises. In this study, measuring the flexibility of an industrial enterprise is related to the dependence on the management of intellectual capital.

To solve this problem is established the effectiveness of the implementation of intellectual capital and some tools and measures of flexibility of industrial enterprises through the elements of intellectual capital. AHP is used as the main tool for selection and evaluation.

A practical application of the analytical hierarchy process is presented to determine the position of flexibility and to develop a strategic vision for the 
development of an industrial enterprise. A system of evaluation and selection criteria is proposed. Their specific values are taken into account in consideration of the power of influence of internal and external factors, depending on the peculiarities of the activity of enterprises and the conditions of the environment in which they they operate. A conditional example is presented, which simultaneously takes into account the impact of a number of criteria and sub-criteria used. On this basis, it is possible to develop alternative strategies depending on the relative importance of the criteria. The alternative strategies are tailored to the weight of the relevant sub-criteria and their degree of influence on the relevance of each criterion.

The computational procedure presented in this study represents the completed first stage of defining the position of flexibility and developing a strategic vision for the development of an industrial enterprise. Also shown is testing a way to form an overall system of criteria for deciding to choose a strategy for increasing the flexibility and adaptability of an industrial enterprise with an emphasis on the impact of intellectual capital.

The second stage of the study involves the development of a method and toolkit to take into account the extent to which the strategy chosen satisfies the other subcriteria in the criterion identified with the highest relative weight. It will be carried out within the second phase of the research project entitled Study of the Opportunities for Building and Management of Flexible Small and Medium Enterprises in Bulgaria.

\section{References}

Bernardes, E. S. \& Hanna, M. D. (2009). A theoretical review of flexibility, agility and responsiveness in the operations management literature. International Journal of Operations \& Production Management, ISSN: 0144-3577, Vol. 29 No. 1, pp. 30-53 Brown, S. \& Bessant, J. (2003). "The manufacturing strategy - capabilities links in masscustomization and agile manufacturing: an exploratory study", International Journal of Operations \& Production Management, ISSN: 0144-3577, Vol. 23 No. 7, pp. 707-30.

Coulson C. (2002). Transforming the Company Manage Change, Compete and Win, Second edition, British Library ISBN 074943651 4, International Journal for Science, Technics and Innovations for The Industry, Published by Scientific Technical Union of Mechanical Engineering, Year XIII, Issue 8/2019, ISSN Print 1313-0226; ISSN Web 1314-507X, pp 354-357.

Dimitrova, K., Panayotova, T. \& Veleva, N. (2019). Study of the Opportunities for Building and Management of Flexible Small and Medium Enterprises in Bulgaria.

Goldman, S. L. \& Nagel, R. N. (1993). "Management, technology, and agility: the emergence of a new era in manufacturing", International Journal of Technology Management, ISSN: 1741-5276, Vol. 8 Nos 1/2, pp. 18-38.

Liebowic, J. \& Ching. S. (2000). Developing Knowledge Management Metrics for Measuring Intellectual Capital, Journal of Intellectual Capital, Vol. 1, No 1, 2000, pp. 54-57. 
Panayotova, T. \& Dimitrova, K.: A Strategic Vision for Development of Flexible In...

Markovic, M[ilivoj]; Draskovic, N[ikola] \& Gnjidic, V[ladimir] (2018). Product Innovation, Process Innovation and Competitive Lessons from Consumer Electronics Industry, Proceedings of the 29th DAAAM International Symposium, pp.0004-0008, B. Katalinic (Ed.), Published by DAAAM International, ISBN 978- 3-902734-20-4, ISSN 1726-9679, Vienna, Austria DOI: 10.2507/29th.daaam.proceedings.001

Panayotova, T., (2016). Value creation in industrial enterprises in North-East region through Intellectual capital resources. Annual Journal of Technical University of Varna, 2016, Vol. 1, ISSN: 1311-896X, http://www2.tu-varna.bg/tuvarna/index.php/izdatelska-deinost/2018-02-12-08-19-09/2018-02-12-07-47-48, pp 52-57;

Panayotova, T., Velev, M. \& Andreev, O. (2011). Using AHM Approach to Position CODP, First International Symposium on Business Modeling and Software Design, Proceeding of BMSD 2011, http//www.is-bmsd.org, ISBN 9789898425683, printed in Portugal, 2011, 80-88;

Panayotova, T., (2004). Organizational Connections Modeling in Complex Reengineering Projects. Dissertation thesis. Sofia.

Pulic, A. (2004). Intellectual capital - does it create or destroy value?. Journal of Business Performance Management, vol.8, No.1.

Roos, G., Pike, S. \& Fernstrum L. (2005). Managing Intellectual Capital in Practice. Butterworth-Heinemann, Elsever Inc.

Saaty, (1980). The Analytic Hierarchy Process, McGrow Hill.

Schwab, K., (2018). The Global Competitiveness Report published by the World Economic Forum 2018;

Stevenson, W. \& Ozgur, C. (2007). Introduction to Management Science with Spreadsheets. McGraw Hill

Stewart, T. (1997). Intellectual capital. The new wealth of organizations. New York. Doubleday/ Currency.

Sushil (2001) Enterprise Flexibility, Global Journal of Flexible Systems Management, 2(4), 53-58.

Sushil \& Chroust , G. (2014). Systemic Flexibility and Business Agility, Springer, ISBN 8132221516, 9788132221517.

Sushil \& Edward, A. (2013). The Flexible Enterprise, Springer Science \& Business Media, ISBN 8132215605, 9788132215608.

Sveiby, K. (1997). The New Organizational Wealth: Managing and Measuring Knowledge- Based Assets. San Fransisco: Berrett-Koehler Publishers Inc.

Volbreda, H. (1998) Building the Flexible Firm: How to Remain Competitive, Oxford University Press, Oxford.

www.bontis.com

Dancheva, A., Dimitrova, D., Jordanova, E., Nikolova, G., Gergova, M., Kolev, M., Panagonova, N., Petkova, R., Filipovich, S., Kateliev, S., Kavgadzhijska, S., Mastikova, S., Davidkov, T. \& Stoyanova, V. (2019. Statistical Reference Book (2019), ISSN 1313-9434, National Statistical Institute, Ilkova, A. (Ed.), pp 266-267. 